\title{
Culture, religion and psychosis - a case study from Limpopo Province, South Africa
}

Culture and religion may impact on mental health. A case from Limpopo province is described with the aim of informing and alerting medical and nursing practitioners working in rural South Africa (with relevance no doubt to other similar African settings) to the dynamics of the case that may warrant more comprehensive attention and consideration, than may be generally afforded in the routine dualistic clinical assessment of patients.

Two sisters of 19 and 22 years of age were brought to the casualty department of a Limpopo hospital by the police. With them were also the two children of the elder sister. They were agitated, hostile, guarded and un-cooperative, pacing up and down, preaching loudly, and refusing to speak to anyone but each other. When they became violent they had to be sedated. The children were removed to the paediatric ward.

The following morning both were calm, relevant, appropriate and cooperative with no symptoms of psychosis. Both gave the same history claiming that their mother had been abducted by strangers the previous day. It turned out that their mother had been removed from their home by relatives and the police in a similar state and admitted to a hospital closer to home. We arranged a transfer to our unit for her immediately. On arrival she had no symptoms of psychosis and medication was stopped. Routine blood investigations were normal and drug screening negative in all three patients.

It emerged that the two sisters and their mother were living in a remote rural village in Limpopo province. The younger sister was a student of tourism at a local university and had been baptised the year before in the Zion Christian Church. She was pointed out as a prophet by the elders shortly thereafter.

Now, a year later, she attended a ZCC service three days before admission and was told by a minister that something bad was about to happen to the family and that they needed to do a church ritual. She was given brewed tea and a box of tea leaves. She returned home and told her mother and sister. Thereafter they locked themselves in the house, drank the tea and engaged in intensive prayer and fasting for three days. The mother related many stories about witchcraft and how it could affect them. On the third day the younger sister saw a broom and a razorblade fall out of her Bible. All three of them saw people disguised as chickens entering their yard on the third day who left after fervent prayer.

\section{Correspondence}

Dr. C Grobler

email: dr.stof@mweb.co.za
The aunt, who lived down the street, was alerted by the neighbours about strange goings on at her sister's house. A known traditional healer, she was previously suspected of "bewitching" them for withdrawing monetary support. When she arrived to investigate, the younger sister realised through a prophetic vision that this was not their aunt but an impostor with huge horns growing out of her head. They attacked her and she fled. The aunt returned to the house with the police. They were only able to apprehend the mother and one child, but the two sisters put up strong resistance and managed to flee with the other two children.

They travelled to Moria, the main seat of the Zion Christian Church movement, where they were turned away because a new born baby was not allowed to enter the "holy place". Left stranded, they spent the night at the local Police station and were sent on the road to go home the following morning, only to be picked up again by the Police when the community alerted them to the strange behaviour of the two women.

None of the three individuals had a history of mental illness before the incident and there was no family history of mental illness.

Management consisted of individual and family sessions, the psychiatrist trying to gain an understanding of their worldand religious views, gently confronting the reality of the situation which led to their admission. They responded well and were discharged within a week on no medication.

Unfortunately none of them returned for follow-up a month later. On enquiry the younger sister had returned to University and refused to come back, claiming she was fine and not in need of help. The mother and sister had entered Moria and were apparently staying there indefinitely.

Cases like these probably rarely come to the attention of a psychiatrist as they are mostly dealt with at rural hospitals without access to specialist support. Even though they came to our attention as psychiatrists, they nonetheless presented a diagnostic challenge. Contemporary psychiatry with its predilection for insisting on an "organic" cause for psychotic illness would have the clinicians involved immediately looking to current diagnostic manuals for making a diagnosis. However, we found no current nomenclature that satisfactorily explained this case.

Shared psychotic disorder, also known as folie a deux, came to mind first. Where a whole family is involved, thought to be especially rare, the disorder is known as folie a famille. ${ }^{1}$

Current accepted definitions of delusions exempt religious doctrines i.e. "a delusion is a false belief based on incorrect inference about external reality that is firmly sustained despite what almost everyone else believes and despite what 
constitutes obvious proof of evidence to the contrary. The belief is not one ordinarily accepted by other members of the person's culture or subculture (e.g. it is not an article of religious faith)."2

In this instance there were no clear delusions. The three women from this close-knit family belong to a certain culture and adhere to certain cultural and religious views which are interwoven in an exceptionally complex way. In their culture "bewitchment" is a commonly accepted belief and taking certain "faith steps" or so-called "rituals" prescribed by faith healers is common practise.

Brief Psychotic Disorder is defined in the DSM-IV-TR as a psychotic condition that involves the sudden onset of psychotic symptoms, lasting from 1 day to 1 month, with an eventual return to pre-morbid levels of functioning. ${ }^{4}$ Whilst thought to be an uncommon disorder the incidence in developing countries is reported to be 10-fold higher than in industrialized countries. ${ }^{5}$

In the assessment of psychiatric patients, the DSM IV-TR also include V-codes and in particular: "Religious and spiritual problem" (V62.89), which, although not a psychiatric diagnosis, serves to formulate these type of problems as a primary focus of clinical attention. ${ }^{4}$ One has to accept that "cultural" issues are, in fact, inherently also religious or spiritual in nature. The V-code option allows for not having to focus on an "organic cause," while not ignoring the prominence of cultural-religious-spiritual matters in a clinical setting. The DSM IV-TR does remind that a psychiatric diagnosis cannot be confirmed, unless presenting symptoms have been considered in the context of what is considered "normal" behaviour within a particular cultural-religious milieu.

The formulation which follows could serve as a possible explanation for their behaviour. The family was vulnerable based on their background of poverty and isolation. The youngest daughter may have been viewed as "special" within her family, being the first one to go on to tertiary level education. Just prior to the incident, she is warned that "something bad" is going to happen to the family and they are given a herbal drink (essentially caffeine based) as a sort of spiritual antidote. This is the precipitating factor which sets the family in motion to deal with the threat as best as they can. The situation becoming aggravated by fasting, sleep deprivation, caffeine laden tea intake, incessant praying, seclusion and unchecked anxieties without reality check, resulting in visual distortions, intense anxiety and a fight/flight response, quite possibly related to a delirious state.

When rejected at Moria, they had nowhere to turn to and ended up roaming the streets. The accumulation of all this stress could well have triggered some sort of transient psychotic state.

The question arising from all of this is: does one need to make a psychiatric diagnosis at all in this particular case? A diagnosis infers a "disorder" of some kind but the prevailing feeling after reviewing this case was one of extreme fear on the part of the individuals involved but no specific mental illness.

This case should remind medical and nursing practitioners alike to remain open-minded, obtain proper histories, observe, engage the patient, be sensitive to cultural issues and beliefs and refrain from the habitual prescription of antipsychotic medication.

Working in predominantly rural South Africa, one is in danger of being so intent on modern psychiatry that one easily forgets about and ignores the wealth of psychopathology unique to this country and Africa. We forget about the impact of belief systems (witchcraft and religion) on the daily life of people, the tensions within the extended family systems and the dynamics of rural communities. All of which contribute to the mental health or ill-health of the people in remote rural areas.

C Grobler, EA Weiss, E Lebelo, E Malerotho Polokwane/Mankweng Hospital Complex Polokwane, South Africa

\section{References}

1. Katsigiannopoylos $K$ et al. Induced delusional disorder: a case report of Folie A' Famille. Poster presentation from International Society on Brain and Behaviour: 2nd International Congress on Brain and Behaviour Thessaloniki, Greece. 17-20 November 2005. Annals of General Psychiatry 2006, 5(Suppl 1):S276.

2. Pierre JM. Faith or delusion? At the crossroads of religion and psychosis. Psychiatr Pract 2001;7(3):163-172.

3. Sadock BJ, Sadock VA. Kaplan and Sadock's Synopsis of Psychiatry: Behavioral Sciences/Clinical Psychiatry. 10th ed. Philadelphia: Lippincott Williams and Wilkins; 2007: 510 - 511.

4. American Psychiatric Association. Diagnostic and Statistical Manual of Mental Disorders. 4th ed. Text revised. Washington DC: American Psychiatric Association. 2000.

5. Susser E, Wanderling J. Epidemilogy of nonaffective acute remitting psychosis vs. schizophrenia. Sex and sociocultural setting. Arch Gen Psych 1994; 51 (4) : 277 - 279. 